\title{
Involving the patient: A prospective study on use, appreciation and effectiveness of an information system in head and neck cancer care
}

\author{
Jaap L. van den Brink ${ }^{a, b, *}$, Peter W. Moorman ${ }^{a}$, Maarten F. de Boer ${ }^{b}$, \\ Jean F.A. Pruyn ${ }^{c}$, Carel D.A. Verwoerd ${ }^{b}$, Jan H. van Bemmel ${ }^{a}$
}

a Department of Medical Informatics, Erasmus MC, Dr. Molewaterplein 50, P.O. Box 1738, 3000 DR

Rotterdam, The Netherlands

b Department of Otorhinolaryngology, Erasmus MC, Dr. Molewaterplein 40, P.O. Box 2040, 3000 CA

Rotterdam, The Netherlands

' Institute for Health and Environmental Issues (IGO), Hoeksestraat 26, 4721 SP Schijf, The Netherlands

Received 10 January 2005; accepted 22 March 2005

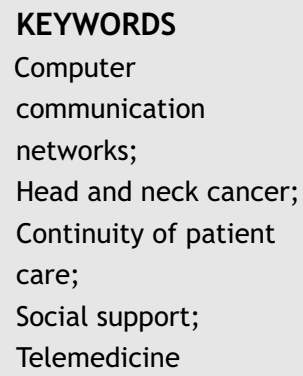

\begin{abstract}
Summary
Objective: To determine use, appreciation and effectiveness of an electronic health information support system in head and neck (H\&N) cancer care.

Design: A prospective evaluation study. The evaluated system has four different functions: (1) communication amongst health care providers and between health care providers and patients, (2) information for health care providers and patients, (3) contact with fellow sufferers and (4) monitoring of discharged patients by means of electronic questionnaires. Evaluation of the system was done both objectively using automatically created log files and stored messages, and subjectively by using paper questionnaires from patients and general practitioners (GPs).

Setting: Department of Otorhinolaryngology and Head and Neck Surgery of a tertiary health care centre in the Netherlands. The system was put at patients' disposal for a period of 6 weeks following discharge from the hospital after surgery for H\&N cancer, and was additional to standard care.

Participants: Head and neck cancer patients, hospital physicians, members of a hospital-based support team, GPs, district nurses and speech therapists.

Main outcome measures: Actual use of the system by patients and health care providers. Patients' appreciation for each of the system's four different functions. GPs' appreciation for the system. Capability to detect potential patient problems with the system.
\end{abstract}

* Corresponding author. Tel.: +31 10408 7050; fax: +31 104089447.

E-mail addresses: j.vandenbrink@erasmusmc.nl (J.L. van den Brink), p.moorman@erasmusmc.nl (P.W. Moorman), m.f.deboer@erasmusmc.nl (M.F. de Boer), igo.pruyn@wxs.nl (J.F.A. Pruyn), kroeskarper@hotmail.com (C.D.A. Verwoerd), j.h.vanbemmel@ext.eur.nl (J.H. van Bemmel). 
Results: The system was used by $36 \mathrm{H \& N}$ cancer patients, 10 hospital physicians, 2 members of the support team, $8 \mathrm{GPs}, 2$ district nurses and 2 speech therapists. The total number of patient-sessions was 982: an average of 27.3 sessions per patient during the 6 weeks study period.

In total, 456 monitoring questionnaires were completed. The support team in hospital responded with 231 actions. In 16 cases, an extra appointment was made for a patient with the hospital physician. Out of these cases, immediate action was considered necessary eight times.

Patients appreciated the system highly, rating it with an average score of 8.0 on a 10 -point scale. All patients used the monitoring function, and rated 'monitoring' with a mean score of 8.0 on a 10 -point scale. Least used and appreciated was the 'contact with fellow sufferers' function.

Only 8 out of possible 36 GPs used the system, rating it with an average of 5.6 on a 10-point scale.

Conclusions: The electronic health information support system was used intensively and highly appreciated by H\&N cancer patients. The system enabled the early detection of occurring health problems that required direct intervention. ICT can play an additional role in the management of patients, also in a relatively elderly and computer illiterate patient population.

(c) 2005 Elsevier Ireland Ltd. All rights reserved.

\section{Introduction}

Many researchers have argued that Information and Communication Technology (ICT), in principle, is able to solve the communication and co-ordination needs of health care $[1,2]$. However, adequate evaluation of most ICT-projects in health care is lacking [3], and 'research goals are often limited to proving the feasibility of implementing new technology' [4]. Besides, evaluation of ICT in health care is generally considered as complex [5].

In head and neck (H\&N) cancer care, many information and communication bottlenecks exist $[6,7]$. A well-recognised problem in multidisciplinary H\&N cancer care is that as many as twenty different disciplines may be involved in the management of a patient [6]. When many care providers are involved, inter professional communication often is sub-optimal [8]. As a result, care is rarely functionally integrated [9]. Especially the period following discharge is a communication 'pitfall': the patient is transferred from a well looked after hospital bed to the home environment, where the care providers usually have little experience in H\&N cancer.

Based on an analysis of the information and communication bottlenecks in H\&N cancer care we designed, and subsequently built, an electronic health information support system [10].

In this paper, we report the actual use of the system. We focus on two questions. First, we assessed patient involvement by investigating the use and appreciation of the system by the patients. Second, we explored whether the system enabled the early detection of potential health problems of patients who were discharged from the hospital after surgery for H\&N cancer.

\section{Methods}

\subsection{Functional description of the electronic health information support system}

Prior to the study, we developed an electronic health information support system for H\&N cancer patients and their health care providers. The system was designed to:

1. facilitate communication between all involved health care providers and between health care providers and patients;

2. provide information to health care providers and patients;

3. facilitate contact with fellow sufferers;

4. facilitate the early detection of patient problems by means of monitoring.

Access to the functions 'communication' and 'monitoring' was restricted to authorised users only, whereas the functions 'information' and 'contact with fellow sufferers' were readily accessible to anyone with access to the Internet.

In this paper, only a limited description of the system's functionality is given. For an extensive description of this system, including an overview of the bottlenecks in H\&N cancer care, and considerations on the protection of patient data see: [10]. 


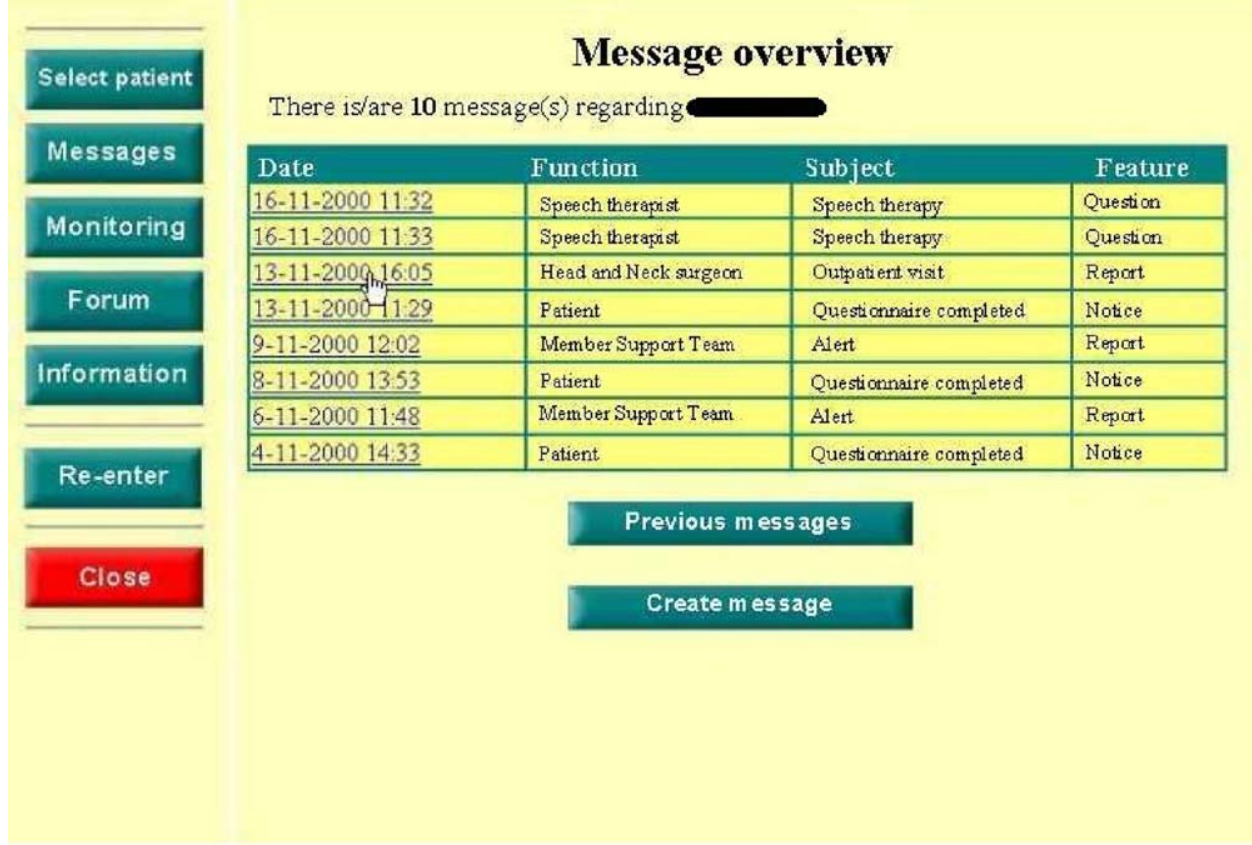

Fig. 1 Translated screen capture of the message overview presented to a user when consulting the message history. In this example, the overview shows 8 (out of 10) selected messages of a single patient. By clicking on the date/time box, the user opens the free text message for reading.

\subsubsection{Communication}

Both patients and health care providers were able to create 'messages'. For each message, the user indicated the subject and the type of message. A message could be typified as 'report', 'question', 'answer', 'medication change', or 'other'. Messages themselves were in free text.

Messages were not sent from one user to another, but all messages were stored centrally; each patient had an own 'P.O. Box' to which authorised users had access. This allowed both patients and authorised health care providers to read all patient-related messages. Fig. 1 shows the message overview presented to a user when consulting the message history.

\subsubsection{Information}

Information for patients and health care providers was supplied by a specially developed website containing general information on cancer, information on H\&N cancer, treatment of H\&N cancer, rehabilitation after treatment and links to other relevant websites. Experts in the field of H\&N cancer had first carefully reviewed the information to ensure its reliability.

\subsubsection{Contact with fellow sufferers}

To enable contact with fellow sufferers, we created a forum. Patients could discuss any subject, either anonymously, or under their own name.

\subsubsection{Monitoring}

Patients were asked to complete electronic monitoring questionnaires on a regular basis after they were discharged from the hospital. Questionnaires provided information about the medical and psychological condition of the patient at home. The content of the questionnaire depended on the type of surgery that a patient had undergone, the time elapsed since discharge and previous answers given by the patient. Most questions were of the multiplechoice type. A few questions could be answered in free text; for example, when patients had any questions or worries. Fig. 2 shows an example of a question that is asked during monitoring.

Every time a patient had completed an electronic questionnaire, a message was automatically added to the patient's personal 'P.O. Box', indicating that the patient had completed a questionnaire. By clicking on this message, users could read all answers given by that patient.

\subsubsection{E-mail alerts}

All possible patient answers of the multiple-choice type had in advance been classified as being 'normal' (not alarming) or 'abnormal' (pointing to a potential problem or complication). All answers in free text were considered 'abnormal' as they could contain questions or worries from the patient.

Every time a completed questionnaire contained one or more 'abnormal' answers, or whenever any 
Did you, during the last few days, experience more pain during swallowing than before?

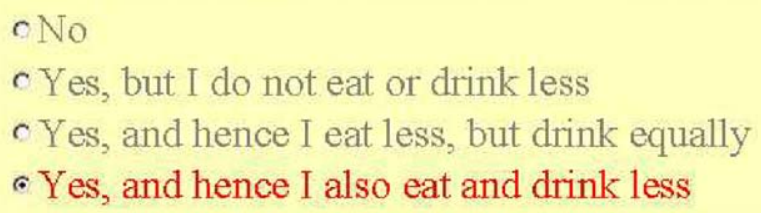

Fig. 2 Translated screen capture of a question that is asked during monitoring. In this example, the patient answers the question: 'Did you, during the last few days, experience more pain during swallowing than before?' by: 'Yes, and hence I also eat and drink less'. The answer is highlighted after it has been selected.

user had sent a message of the type 'question', the system automatically generated an e-mail alert, which was sent to a support team in the hospital. This support team consisted of two nurses specialised in home care technology. The team responded according to a predetermined protocol. This protocol described which action should be undertaken in which circumstances. For example, the support team might make an extra appointment for the patient with the specialist, inform or reassure the patient, or arrange for the GP to visit the patient. Members of the support team always contacted the patient by phone and added a message ('report') to the patient's personal 'P.O. Box'.

Whenever a patient had not filled in the electronic monitoring questionnaire for 4 days or more, the system also automatically sent an e-mail alert to the support team.

\subsection{Research setting}

Patients were included from September 2000 to January 2002.

Patients were eligible to participate when they had undergone:

1. a laryngectomy (removal of the speech organ),
2. a commando-procedure (removal of a tumour in the mouth or throat by splitting the lower jaw), or

3. a neck dissection (removal of the lymph nodes in the neck).

Patients furthermore needed to be able to read and write Dutch, and have a phone at home. All surgeries were performed at the Daniel den Hoed Oncology Clinic of Erasmus MC (Erasmus University Medical Centre), a tertiary health care centre in Rotterdam, the Netherlands.

Included patients received standard care: scheduled visits to our outpatient clinic, typically at 2 and 6 weeks after discharge. Additionally, we offered patients a laptop personal computer with modem to be used at home for a period of 6 weeks from discharge. Before discharge, a medical student instructed the patient in the hospital and supervised while the patient practised the use of the system. Furthermore, the members of the support team personally introduced themselves to the patient.

The laptop was programmed to launch the dialin connection on start-up and go to the main screen of the system. This main screen gave access to each of the four different functions (Fig. 3). The phonein number was free of charge. All involved health 


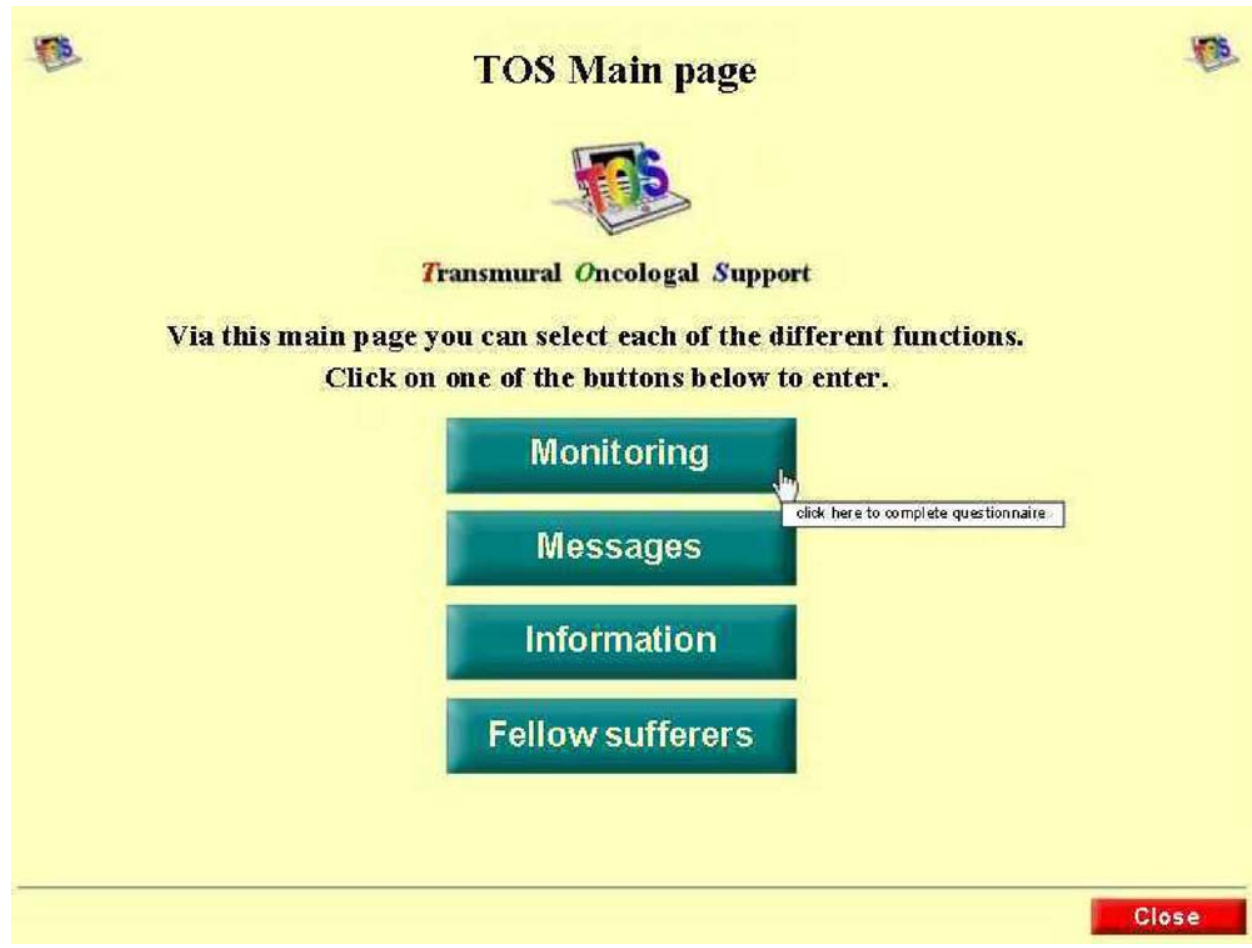

Fig. 3 Translated screen capture of the main screen for patients.

care providers also received information on how to use the system and they were provided with access passwords. GPs could enter the system using their own computer or via the patient's laptop. For all users, a telephone helpdesk was available during office hours.

\subsection{Evaluation}

Patients who refused to participate in our study were requested to indicate their reason. We asked all included patients to provide the following data:

-the type of surgery that the patient had undergone;

-gender, age and marital status;

-level of education (on an 8-point scale);

-experience with computers ('none', 'a little', 'quite a bit', or 'a lot').

Evaluation of the system was conducted in two different ways:

1. by analysing the log files and by evaluating all messages and e-mail alerts;

2. by means of a paper-based questionnaire addressing the use and appreciation of the system.

\subsubsection{System use}

The system created automatic log files. From these log files, we determined:

-who had used the system and when;

-the number of sessions for each user (every new entry into the system by any single user was defined as 'a session');

-the average number of sessions (as well as standard deviation and range);

-the average duration (and range) of the patients' sessions.

\subsubsection{Messages}

We counted the total number of messages. For all patient messages, we determined the type (e.g., 'question' and 'report') and content of each message. Messages from health care providers were analysed in a similar way. Furthermore, the average number of completed electronic monitoring questionnaires per patient was computed.

\subsubsection{Monitoring}

We determined the percentage of electronic monitoring questionnaires that had evoked one or more e-mail alerts (pointing at potential patient problems), and we explored which questions had evoked how many e-mail alerts. 


\subsubsection{Actions of the support team}

By reading all free text messages sent by the support team and the health care providers, we analysed what types of action the support team had undertaken. Next, we explored all messages created by the ENT physicians in order to determine whether the system had been able to detect patient problems that required direct medical intervention.

\subsubsection{Questionnaires addressing use and appreciation of the system}

When patients returned their laptop computer at around 6 weeks after discharge, they were asked to complete a paper questionnaire addressing use and appreciation of the system. At the same time, GPs were sent a similar questionnaire that could be returned by mail free of charge.

The patients' questionnaire contained 22 questions, mostly multiple-choice. Amongst others, patients were asked to describe which of the system's four functions they had used and how they valued each function separately, as well as the system as a whole (by giving a score from 1 to 10). Average, median and range for all scores were computed.

The GPs' questionnaire contained 16 questions, mostly multiple-choice. We asked GPs who had used the system, to rate the system on a 10point scale, and to indicate whether they had used their own computer or the patient's laptop. All GPs were asked whether they expected that ICT would increasingly play an important role in transmural oncological care.

\section{Results}

During the inclusion period, 59 patients met the inclusion criteria. From these 59 patients, 20 refused to participate (inclusion of $66 \%$ ). Of the 20 patients who refused to participate 15 were male and 5 were female.

Table 1 lists the reasons for refusal. Three patients stopped shortly after inclusion, two were too tired to participate and one patient died. Thus, 36 patients remained for evaluation of the electronic health information support system.

Table 2 describes the patients' characteristics $(n=36)$ : 26 patients were male, 10 patients were female and the average age was 59 years (range $38-78)$. Twenty of the 36 patients (56\%) had no experience with computers before participation.
Table 1 Reasons for patients' refusal to participate in this study

\begin{tabular}{ll}
\hline Reason for refusal & Number of times \\
\hline Computer phobia & 9 \\
Tiredness/needing some rest & 4 \\
Does not like the idea of filling & 2 \\
$\quad$ in paper questionnaires & \\
Looks after demented parent & 1 \\
Moving house & 1 \\
Partner does not allow patient & 1 \\
$\quad$ to have access to a computer & \\
No time (company ownership) & 1 \\
Afraid for theft of laptop & 1 \\
$\quad$ computer & \\
\hline
\end{tabular}

\subsection{System use}

Ten hospital physicians, seven GPs, two speech therapists, two district nurses, two members of the support team, one medical student and one researcher used the system. Total number of sessions for GPs, speech therapists, hospital physicians and support team members were 13, 32, 158 and 460 , respectively.

All 36 patients used the system. The total number of patient-sessions was 982 . The average number of sessions per patient was 27.3 (S.D. 18.4, range 4-69) in the 6 weeks study period. On average, a patient-session lasted $12 \mathrm{~min}$. The longest patient-session lasted $1 \mathrm{~h}$ and $38 \mathrm{~min}$. Of all patientsessions, $16 \%$ took place after office hours (between 19:00 and 07:00 h).

\subsection{Messages}

In total, 994 messages were sent, of which 456 were results of monitoring questionnaires answered by patients.

On average, each patient completed 12.6 questionnaires. In addition to monitoring questionnaires, 21 patients sent additional messages. These 21 patients, on average, sent 4.5 messages. Half of these messages contained a question and half were personal reports on how the patient was doing. Two patients sent a 'test question' to test the response.

Hospital physicians sent, on average, 2.6 messages per patient. For two patients, they did not send any messages. Messages included discharge reports, patient visits reports and answers to patient questions. In four cases, a message was used to communicate results of tests.

Six GPs sent on average 2.0 messages, 3 of these messages were questions. 
Table 2 Patients' characteristics

\begin{tabular}{|c|c|c|c|c|c|c|}
\hline Number & Operation type & Gender & Age (years) & Marital status & Level of education & Computer experience \\
\hline 1 & Neck dissection & $M$ & 68 & Married & 3 & None \\
\hline 2 & Neck dissection & $\mathrm{F}$ & 70 & Married & 2 & None \\
\hline 3 & Laryngectomy & M & 53 & Married & 3 & None \\
\hline 4 & Laryngectomy & $\mathrm{F}$ & 78 & Widow & 5 & None \\
\hline 5 & Commando & $M$ & 51 & Married & 7 & A little \\
\hline 6 & Laryngectomy & $M$ & 74 & Married & 3 & Quite a bit \\
\hline 7 & Laryngectomy & M & 49 & Single & 5 & A lot \\
\hline 8 & Laryngectomy & M & 68 & Widower & 3 & None \\
\hline 9 & Neck dissection & M & 64 & Married & 2 & None \\
\hline 10 & Neck dissection & $M$ & 51 & Married & 3 & None \\
\hline 11 & Laryngectomy & $M$ & 67 & Married & 2 & None \\
\hline 12 & Laryngectomy & $\mathrm{F}$ & 52 & Married & 3 & None \\
\hline 13 & Laryngectomy & M & 54 & Married & 4 & Quite a bit \\
\hline 14 & Commando & $M$ & 38 & Divorced & 6 & A lot \\
\hline 15 & Laryngectomy & M & 68 & Single & 2 & None \\
\hline 16 & Laryngectomy & $\mathrm{F}$ & 44 & Married & 2 & None \\
\hline 17 & Neck dissection & $M$ & 57 & Married & 3 & A little \\
\hline 18 & Neck dissection & $M$ & 65 & Divorced & 6 & Some \\
\hline 19 & Commando & $\mathrm{F}$ & 52 & Married & 3 & A little \\
\hline 20 & Neck dissection & $\mathrm{F}$ & 54 & Married & 3 & A little \\
\hline 21 & Neck dissection & $M$ & 53 & Married & 3 & None \\
\hline 22 & Laryngectomy & $M$ & 74 & Married & 4 & A little \\
\hline 23 & Neck dissection & $M$ & 39 & Married & 8 & A lot \\
\hline 24 & Neck dissection & $\mathrm{F}$ & 57 & Widow & 4 & None \\
\hline 25 & Commando & $\mathrm{F}$ & 74 & Married & 4 & None \\
\hline 26 & Laryngectomy & $M$ & 55 & Married & 2 & None \\
\hline 27 & Laryngectomy & $M$ & 64 & Married & 4 & None \\
\hline 28 & Commando & $M$ & 70 & Married & 6 & Quite a bit \\
\hline 29 & Neck dissection & $M$ & 73 & Married & 7 & A little \\
\hline 30 & Neck dissection & $M$ & 58 & Married & 3 & A little \\
\hline 31 & Commando & $M$ & 51 & Married & 3 & None \\
\hline 32 & Neck dissection & $\mathrm{F}$ & 57 & Divorced & 4 & Quite a bit \\
\hline 33 & Laryngectomy & $M$ & 71 & Single & 7 & None \\
\hline 34 & Commando & $M$ & 54 & Married & 3 & None \\
\hline 35 & Neck dissection & $M$ & 41 & Married & 8 & A lot \\
\hline 36 & Neck dissection & $\mathrm{F}$ & 56 & Married & 3 & None \\
\hline
\end{tabular}

Level of education-1: no education, 2: elementary school, 3: lower technical school, 4: secondary education, 5: middle technical training, 6: high school/college, 7: higher education, 8: university level.

For nine patients, the speech therapists sent messages: in those cases the average was 2.9 messages.

\subsection{Monitoring}

Of the 456 monitoring questionnaires, 187 (41\%) evoked an e-mail alert as a result of 'abnormal answers'. In two patients, none of the monitoring questionnaires evoked such an alert. Table 3 shows the questions in the monitoring questionnaire that had evoked e-mail alerts.

\subsection{Actions of the support team}

For 34 of the 36 patients the team had to respond to questions or e-mail alerts: in total 231 actions.
In $81.7 \%$ of the 231 cases requiring action, the patient's question could be answered, advice could be given, the patient could be reassured, or the patient already had an appointment to be seen in hospital within a short time.

In 17 cases, an extra appointment was made for the patient: 6 times the same day, 7 times within 2 days, 3 after more than 2 days and 1 with the GP. In 8 of the 16 hospital cases, the ENT physician considered it necessary to undertake direct further action, after having seen the patient. Leaking speech prostheses were replaced twice, in three cases the patient was referred to physiotherapy, one patient received antibiotics for a wound infection, one patient received a nasogastric feeding tube and one patient was referred to a dietician. 
Table 3 Subjects of questions generating e-mail alerts

\begin{tabular}{ll}
\hline Subject of question & $\begin{array}{l}\text { Number of } \\
\text { e-mail alerts }\end{array}$ \\
\hline Pain during swallowing & 52 \\
Open question about worries & 36 \\
Open item to let something be & 34 \\
$\quad$ known & \\
Coughing in relation to food intake & 32 \\
$\quad$ or cannula insertion & \\
Speech problems & 30 \\
Shortness of breath & 27 \\
Requesting additional information & 25 \\
Pain in head and neck & 21 \\
Problems with dental prosthesis & 20 \\
Problems with insertion of cannula & 18 \\
Difficulties in swallowing & 18 \\
Psychosocial issues (seven different & 17 \\
$\quad$ questions) & \\
Lumps or swelling in the head and & 16 \\
$\quad$ neck region & \\
Viscous mucus & 13 \\
Pain in shoulder & 13 \\
Tiredness/fatigue & 8 \\
Skin sensitivity & 7 \\
Dry mouth & 7 \\
Runny nose & \\
Nasal regurgitation & 6 \\
Hearing difficulties & \\
Loss of taste & \\
Problems in contacting care & 1 \\
providers & 3 \\
\hline a Most questions informed about a 'deteriorating situation \\
since last time'. & \\
&
\end{tabular}

During the study period, three patients had additional problems requiring action. These problems were detected during regular outpatient visits and had not been picked up by monitoring. One patient was admitted for blood transfusion (for low hemoglobin), in one patient the oral flap had become dehiscent and another patient required a nasogastric feeding tube.
For 17 patients, the team had to contact the patient to enquire why the patient had not posted any monitoring questionnaires for 4 days or more.

\subsection{Results from the patients' questionnaire}

All 36 patients filled in the paper-based questionnaire on use and appreciation of the system.

Table 4 shows the subjective patients' view on use and appreciation of the system. The table shows, for example, that of the 36 patients that used the monitoring function, 33 were aware of having received responses from the support team and $31(94 \%)$ of these 33 patients were satisfied with the response. Furthermore, the average score of all patients for the monitoring function was 8.0 on a 10-point scale.

Table 5 shows the other 15 topics in the patients' questionnaire. The table shows, for example, that nine patients $(25 \%)$ encountered (technical) problems while using the system. In these cases, the patients reported that: their system 'did not work anymore' (three times) was 'too slow' (three times), the 'password' had been 'forgotten' (once), 'handling the mouse was difficult' (once) and that the computer 'refused to switch off' (once). The helpdesk solved eight of these nine problems by phone, in one case the patient's laptop was replaced.

Sixteen patients made additional remarks at the end of their questionnaire. Five patients explicitly regretted the fact that they had to return their laptop; they would have liked access to the system for a longer period of time. Seven patients simply gave additional positive remarks. One such remark was: "I am just very glad I could participate. It gave me a substantial feeling of security and I will miss this"'.

\subsection{Results from the GPs' questionnaire}

From the 36 GPs, 31 returned their questionnaire (response rate of $86 \%$ ).

Table 4 Use and appreciation of the electronic health information support system by patients

\begin{tabular}{llll}
\hline Functionality & $\begin{array}{l}\text { Number (percentage) of patients } \\
\text { that used the functionality }\end{array}$ & $\begin{array}{l}\text { Percentage of satisfied } \\
\text { patient users (numbers) }\end{array}$ & $\begin{array}{l}\text { Mean score } \\
\text { (range) }\end{array}$ \\
\hline Monitoring & $36(100)$ & $94(31 / 33)$ & $8.0(2-10)$ \\
Ask questions & $23(64)$ & $91(21 / 23)$ & $7.8(1-10)$ \\
Read messages & $27(75)$ & $89(24 / 27)$ & $7.7(4-10)$ \\
Contact with fellow sufferers & $3(8)$ & $67(2 / 3)$ & $6.7(6-8)$ \\
Information & $22(61)$ & $91(20 / 22)$ & $7.8(1-10)$ \\
Overall score for 'the system as a whole' & & $8.0(4-10)$ \\
\hline
\end{tabular}


Table 5 Additional questions asked in the patients' questionnaire

\begin{tabular}{|c|c|}
\hline Question & Patients' answers (percentages) \\
\hline Did you find it difficult to learn how to use the laptop computer? & $\begin{array}{l}\text { Not difficult at all (61) } \\
\text { Somewhat difficult (28) } \\
\text { Rather difficult (3) } \\
\text { Very difficult (8) }\end{array}$ \\
\hline $\begin{array}{l}\text { Did use of the system result in increased knowledge about your illness } \\
\text { and/or treatment? }\end{array}$ & $\begin{array}{l}\text { Yes }(64) \\
\text { No }(36)\end{array}$ \\
\hline $\begin{array}{l}\text { Did use of the system affect the way in which you have been feeling during } \\
\text { the past few weeks? }\end{array}$ & $\begin{array}{l}\text { Yes, a positive effect (67) } \\
\text { Yes, a negative effect (0) } \\
\text { No effect (33) }\end{array}$ \\
\hline $\begin{array}{l}\text { Do you feel that health care providers, by using the system, have kept a } \\
\text { better eye on your illness? }\end{array}$ & $\begin{array}{l}\text { Yes }(86) \\
\text { No }(14)\end{array}$ \\
\hline $\begin{array}{l}\text { Do you feel that use of the system has enabled you to communicate better } \\
\text { with health care providers? }\end{array}$ & $\begin{array}{l}\text { Yes (75) } \\
\text { No (25) }\end{array}$ \\
\hline $\begin{array}{l}\text { Do you feel that use of the system has led to earlier detection of encoun- } \\
\text { tered problems? }\end{array}$ & $\begin{array}{l}\text { Yes }(53) \\
\text { No (41) } \\
\text { Open (6) }\end{array}$ \\
\hline $\begin{array}{l}\text { Would you advise other patients in similar situations to use the system as } \\
\text { well? }\end{array}$ & $\begin{array}{l}\text { Yes (89) } \\
\text { No (11) }\end{array}$ \\
\hline Did you encounter any technical problems while using the system? & $\begin{array}{l}\text { Yes, ... (25) } \\
\text { No (75) }\end{array}$ \\
\hline $\begin{array}{l}\text { Do you believe that computers have the potential to improve communica- } \\
\text { tion and co-operation between health care providers? }\end{array}$ & $\begin{array}{l}\text { Yes }(86) \\
\text { No }(0) \\
\text { Do not know (14) }\end{array}$ \\
\hline $\begin{array}{l}\text { Did you find it annoying to fill in electronic monitoring questionnaires reg- } \\
\text { ularly? }\end{array}$ & $\begin{array}{l}\text { No, not at all (92) } \\
\text { Yes, somewhat (8) } \\
\text { Yes, a lot }(0)\end{array}$ \\
\hline $\begin{array}{l}\text { Being able to contact health care providers in hospital by means of the } \\
\text { system provided a feeling of security }\end{array}$ & $\begin{array}{l}\text { Yes, a lot (72) } \\
\text { Yes, somewhat (11) } \\
\text { No (17) }\end{array}$ \\
\hline $\begin{array}{l}\text { If the phone-in number had not been free of charge, I would have used the } \\
\text { system }\end{array}$ & $\begin{array}{l}\text { Less often (11) } \\
\text { Just as much (86) } \\
\text { More often (3) }\end{array}$ \\
\hline Do you have any suggestions on how to improve the system? & $\begin{array}{l}\text { Yes, } \ldots(25) \\
\text { No }(75)\end{array}$ \\
\hline $\begin{array}{l}\text { As a result of the last few weeks, do you plan to buy a computer of your } \\
\text { own? }\end{array}$ & $\begin{array}{l}\text { Yes, I already bought one ( } 3 \text { ) } \\
\text { Yes, but I did not buy one yet (22) } \\
\text { No ( } 75 \text { ) }\end{array}$ \\
\hline Do you have any additional remarks? & $\begin{array}{l}\text { Yes, ... (44) } \\
\text { No (56) }\end{array}$ \\
\hline
\end{tabular}

Eight of these $31 \mathrm{GPs}$ had used the system: 2 using their own computer, 6 using the patient's laptop. The fact that eight GPs claimed to have used the system, whereas the log files showed only seven GPs may be the result of one GP using the system with the patient's laptop (with the patient's username and password).

The 23 GP's who did not use the system explained that: there had been no reason to use the system
(12 times), GPs had no time for this (7 times), there had been no contact with the patient (twice), the GP had lost the instructions and password (once) or was not aware of the existence of the system (once).

Seven GPs rated the electronic health information support system with an average score of 5.6 on a 10-point scale (range $1-9$ ). Of the 31 responding GPs, 19 GPs (61\%) expected that ICT will increa- 
singly play an important role in transmural oncological care and 9 GPs (29\%) had 'no opinion' on this.

\section{Discussion}

Involving the patient in the care process using ICT is an active area of research [11-13]. Internet sites with health information, including health discussion groups, are abundant [14-16]. Projects where patients access their electronic medical record [17], send e-mails to their doctors [18-20], or send data to be monitored [21,22], have also been described.

In this paper, we evaluated an electronic health information support system that provides the patient with the ability to communicate with their health care providers and with fellow sufferers, gives the patient access to Internet information, and allows the early detection of potential patient problems. We assessed whether patients used and appreciated the system, and whether the system enabled the early detection of potential patient problems.

The patients in our study used the system intensively (all patients used the system with an average of four to five times a week). Patients also appreciated the system highly (average overall score of 8.0 on a 10 -point scale, and $89 \%$ would advise other patients in similar situations to use the system as well). This, despite their high average age, and the fact that all patients were recovering from an (often mutilating) operation for H\&N cancer. Although there may have been some inclusion-bias (11 patients indicated computer-related reasons for non-participating), the patients in the study group in majority were still relatively computer-illiterate (56\% had no previous computer experience).

The system did allow the early detection of occurring patient problems: in 8 of the 36 patients direct medical actions by the hospital physician were required. This means that in one out of four patients, the system detected patient problems that had not (yet) been discovered during regular outpatient visits. Without the system, these problems could also have been discovered, but later. By then, they possibly could have resulted in adverse events: for example, leaking speech prostheses may cause airway infections. In addition, a wide variety of other issues emerged in which the patient needed reassurance. However, not all problems came to light through the system: three actionrequiring patient problems were identified during routine hospital visits. This finding suggests that ICT should be complementary to, rather than replace, current practice.
GPs in the Netherlands have a long history of ICT use [23] and electronic messaging [24,25]. Of the GPs in our study, $61 \%$ believed that ICT will increasingly play an important role in transmural oncological care. It is therefore disappointing to observe that only $25 \%$ of the GPs used the system. This finding may be explained by the fact that the system was not integrated with the GP's own information system.

Literature shows that contact with fellow sufferers can be beneficial to oncological patients $[26,27]$. Of the four available functions, however, patients used and appreciated 'contact with fellow sufferers' the least. A possible explanation for this finding might be the timing of our study. The first 6 weeks after discharge may well be too soon for patients to appreciate exchanging experiences with other patients, for example, because most attention and energy is still needed for recovering from the operation.

In our study, patient satisfaction for the 'monitoring' and 'ask a question' functions were high: 94 and $91 \%$, respectively. Although patients were asked to fill in electronic monitoring questionnaires two to three times a week, the fast majority $(92 \%)$ indicated that they found this 'not at all' annoying. The timing of our study may explain these findings. Whereas discharge normally brings an abrupt end to having health care providers nearby, the 'monitoring' and 'ask a question' functions emulated the 'hospital bell by the bed' in their home environment. This is also illustrated by the finding that most patients $(83 \%)$ believed that being able to contact care providers by means of the system had provided a feeling of security.

Most patients found learning how to use of the system not difficult at all (61\%). Although personal instruction and the system's ease of use may have contributed, general knowledge in relation to patient satisfaction with telemedicine applications is still limited [28] and requires further research, for example, on the influence on quality of care and life, and on cost effectiveness. The fact that, in this study, an elderly, relatively computer illiterate patient group, in an uncertain phase of their life, appreciated the additional value of ICT in their care shows that such groups should not be excluded.

\section{Acknowledgements}

We would like to acknowledge the skills and dedication in patient care of the members of the Head and Neck Group in the Erasmus MC. The authors wish to thank Professor L. Feenstra, Head of the Department of Otorhinolaryngology, Professor J. 
van der Lei, Head of the Department of Medical Informatics, and J.A. Borgstein, ENT surgeon, for their helpful comments during preparation of this paper. Ineke Elswijk, Helen de Graaf and Roel Streefkerk supported and instructed the patients. Software was implemented and hosted by LifeLine Networks (http://www.lifeline.nl). Funding by 'OntwikkelingsBedrijf Rotterdam' and 'Stichting Roparun' is gratefully acknowledged.

\section{References}

[1] Committee on Quality of Health Care in America IoM, To Err Is Human: Building a Safer Health System, National Academy Press, Washington, DC, 1999.

[2] Committee on Quality of Health Care in America IoM, Crossing the Quality Chasm: A New Health System for the 21st Century, National Academy Press, Washington, DC, 2001.

[3] R.A. Miller, Reference standards in evaluating system performance, J. Am. Med. Inform. Assoc. 9 (2002) 87-88.

[4] W. Hersh, J. Wallace, P. Patterson, Telemedicine for the Medicare Population. Summary, Evidence Report/Technology Assessment: Number 24. AHRQ Publication Number 01-E011, Agency for Healthcare Research and Quality, Rockville, 2001 (available at http://www.ahrq. gov/clinic/epcsums/telemedsum.htm).

[5] C. Friedman, J. Wyatt, Evaluation Methods in Medical Informatics, Springer, New York, 1997.

[6] A. van Wersch, M.F. de Boer, E. van der Does, P. de Jong, P.P. Knegt, C.A. Meeuwis, P. Stringer, J.F.A. Pruyn, Continuity of information in cancer care: evaluation of a logbook, Patient Educ. Couns. 31 (1997) 223-236.

[7] I.E. Wouterlood van Cleeff, M.F. de Boer, P.C. de Jong, J.F.A. Pruyn, L.W. Molendijk, L.L. Visch, P.P. Knegt, Knelpunten in de zorg voor hoofd-halstumorpatiënten (Bottlenecks in providing care to head and neck cancer patients), Medisch Contact 46 (1991) 179-181.

[8] J.P. Hampson, R.I. Roberts, D.A. Morgan, Shared care: a review of the literature, Fam. Pract. 13 (1996) 264-279.

[9] R.H. Fletcher, M.S. O'Malley, S.W. Fletcher, J.A. Earp, J.P. Alexander, Measuring the continuity and coordination of medical care in a system involving multiple providers, Med. Care 22 (1984) 403-411.

[10] J.L. van den Brink, P.W. Moorman, M.F. de Boer, J.H. van Bemmel, J.F.A. Pruyn, C.D.A. Verwoerd, An information system to support the care for head and neck cancer patients, Support Care Cancer 11 (2003) 452-459.

[11] F.M. McTavish, D.H. Gustafson, B.H. Owens, M. Wise, J.O. Taylor, F.M. Apantaku, H. Berhe, B. Thorson, CHESS: an interactive computer system for women with breast cancer piloted with an under-served population, Proc. Annu. Symp. Comput. Appl. Med. Care (1994) 599-603.
[12] J. Starren, G. Hripcsak, S. Sengupta, C.R. Abbruscato, P.E. Knudson, R.S. Weinstock, S. Shea, Columbia University's Informatics for Diabetes Education and Telemedicine (IDEATel) project: technical implementation, J. Am. Med. Inform. Assoc. 9 (2002) 25-36.

[13] M.G. Peterson, R.M. Rippey, A computerized cancer information system, Patient Educ. Couns. 19 (1992) 81-87.

[14] J.I. Fernsler, L.J. Manchester, Evaluation of a computerbased cancer support network, Cancer Pract. 5 (1997) 46-51.

[15] P. Klemm, K. Reppert, L. Visich, A nontraditional cancer support group: the Internet, Comput. Nurs. 16 (1998) 31-36.

[16] J. Norum, A. Grev, M.A. Moen, L. Balteskard, K. Holthe, Information and communication technology (ICT) in oncology. Patients' and relatives' experiences and suggestions, Support Care Cancer 11 (2003) 286-293.

[17] S.E. Ross, C.T. Lin, The effects of promoting patient access to medical records: a review, J. Am. Med. Inform. Assoc. 10 (2003) 129-138.

[18] R.A. Neill, A.G. Mainous, J.R. Clark, M.D. Hagen, The utility of electronic mail as a medium for patient-physician communication, Arch. Fam. Med. 3 (1994) 268-271.

[19] E.A. Balas, F. Jaffrey, G.J. Kuperman, S.A. Boren, G.D. Brown, F. Pinciroli, J.A. Mitchell, Electronic communication with patients. Evaluation of distance medicine technology, JAMA 278 (1997) 152-159.

[20] E.M. Liederman, C.S. Morefield, Web messaging: a new tool for patient-physician communication, J. Am. Med. Inform. Assoc. 10 (2003) 260-270.

[21] J.C. Cherry, T.P. Moffatt, C. Rodriguez, K. Dryden, Diabetes disease management program for an indigent population empowered by telemedicine technology, Diab. Technol. Ther. 4 (2002) 783-791.

[22] P.A. De Clercq, A. Hasman, B.H. Wolffenbuttel, A consumer health record for supporting the patient-centered management of chronic diseases, Med. Inform. Internet Med. 28 (2003) 117-127.

[23] J. van der Lei, J.S. Duisterhout, H.P. Westerhof, E. van der Does, P.V. Cromme, W.M. Boon, J.H. van Bemmel, The introduction of computer-based patient records in The Netherlands, Ann. Intern. Med. 119 (1993) 1036-1041.

[24] P.J. Branger, J.C. van der Wouden, B.R. Schudel, E. Verboog, J.S. Duisterhout, J. van der Lei, J.H. van Bemmel, Electronic communication between providers of primary and secondary care, BMJ 305 (1992) 1068-1070.

[25] P.W. Moorman, P.J. Branger, W.J. van der Kam, J. van der Lei, Electronic messaging between primary and secondary care: a four-year case report, J. Am. Med. Inform. Assoc. 8 (2001) 372-378.

[26] H.W. van den Borne, J.F.A. Pruyn, W.J.A. van den Heuvel, Effects of contact between cancer patients on their psychosocial problems, Patient Educ. Couns. 9 (1987) 33-51.

[27] J.F.A. Pruyn, Coping with stress in cancer patients, Patient Educ. Couns. 5 (1983) 57-62.

[28] F. Mair, P. Whitten, Systematic review of studies of patient satisfaction with telemedicine, BMJ 320 (2000) 1517-1520.

Available online at www.sciencedirect.com

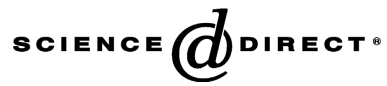

